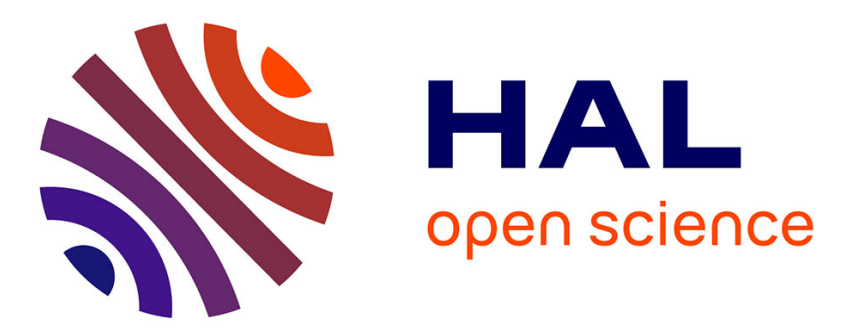

\title{
Assessing the cortical thickness of long bone shafts in children, using two-dimensional ultrasonic diffraction tomography
}

Philippe Lasaygues

\section{- To cite this version:}

Philippe Lasaygues. Assessing the cortical thickness of long bone shafts in children, using twodimensional ultrasonic diffraction tomography. Ultrasound in Medicine \& Biology, 2006, 12 (8), pp.1215-1227. hal-00440682

\section{HAL Id: hal-00440682 \\ https://hal.science/hal-00440682}

Submitted on 27 Apr 2010

HAL is a multi-disciplinary open access archive for the deposit and dissemination of scientific research documents, whether they are published or not. The documents may come from teaching and research institutions in France or abroad, or from public or private research centers.
L'archive ouverte pluridisciplinaire HAL, est destinée au dépôt et à la diffusion de documents scientifiques de niveau recherche, publiés ou non, émanant des établissements d'enseignement et de recherche français ou étrangers, des laboratoires publics ou privés. 
Assessing the cortical thickness of long bone shafts in children, using two-dimensional ultrasonic diffraction tomography

Philippe Lasaygues

Laboratoire de Mécanique et d'Acoustique, UPR CNRS 7051

31 chemin Joseph Aiguier,

13402 Marseille cedex 20 - France

$\underline{\text { Mail address: }}$

Philippe Lasaygues

Laboratoire de Mécanique et d'Acoustique, UPR CNRS 7051

31 chemin Joseph Aiguier,

13402 Marseille cedex 20 - France

Running title: Ultrasonic tomography on bones 


\begin{abstract}
:
Echography is one of the first-line techniques used in clinical practice to diagnose osteoarticular diseases in children. However, this technique involves the use of standard equipment, which is not adapted to the morphology or the acoustical properties of children's bones. In this study, we developed an ultrasonic tomography method for measuring the cortical thickness of children's long bones. Ultrasonic tomography gives cross-sectional images showing the spatial distribution of some of the physical components of an object, based on scattered ultrasound measurements. These measurements are carried out using variably dense sets of transmitter and receiver positions and various the wave frequencies. We solved this inverse scattering problem using a Born approximation, which yields an attractively simple linear relation between the object function and the scattered field, particularly in the far field. Experiments with a 2D-ring antenna show the applicability of the method and its various improvements to bone thickness imaging. (E-mail: lasaygues@lma.cnrs-mrs.fr)
\end{abstract}

Keywords: Ultrasonic tomography, Born approximation, 2D-ring antenna, Children's bones imaging 


\section{INTRODUCTION}

Echography has long been the main first-line imaging technique used to diagnose various pediatric pathologies (such as abdominal injuries, urinary tract problems, congenital cardiac defects and brain anomalies and injuries). In the case of bone diseases, this technique is now proving to be an invaluable means of assessing painful traumatic and non traumatic disorders (such as hip dysplasia, knee trauma and stress fracture of the tibia). Cases where it is necessary to search for an intra articular joint effusion, an infectious periosteal apposition or a tumoral resurgence in contact with a stainless steel prosthesis or, more recently, for a traumatic ligament lesion, are just a few examples where the use of ultrasound is highly indicated (Falcini et al. 2000; Rand et al. 2001; Enns et al. 2004; Halaba and Pluskiewicz 2004; Mayr et al. 2004; May et al. 2004). X-ray computed tomography, magnetic resonance imaging and/or bone scintigraphy, the other widely used methods available (Baert and Sartor 2002), have various disadvantages, depending on the type of examination for which they are used, such as their cost, the fact that they involve X-rays or require sedation and their lack of availability and accessibility. Echography is non invasive, non irradiant, painless, inexpensive and practicable on children in bed. However, there are some factors which make it impossible to extend the use of this technique on patients with other osteoarticular diseases. In practice, it is difficult to perform pediatric bone ultrasonography, because standard echographic devices are not very suitable for use with hyper echogenic tissues of this kind (because of amplification, gain, delay line problems etc.). The usual ultrasonic probes are not always adapted to the morphology of the area investigated (because of the linear array, dimensions, 
time and space resolution). The frequencies used are too high to be able to penetrate into the cortical bone and the underlying tissue (the medullary canal). The echographic map certainly reflects the varying impedance levels between tissues, but it does not depend on information about any particular acoustical parameter.

Many authors have dealt with the ultrasonic characterization and imaging of adults' and children's bones. Their main aim has usually been to assess the thickness of the diaphysis (as part of its geometrical conformation) and to calculate the speed of sound (an acoustical parameter) of a compressional wave crossing the structure. These aspects are both of great importance. For example, the cortical thickness provides an index to the risk of fracture and can serve to predict fracture loads in the radius, femur and lumbar vertebrae (Wear 2003; Stegman et al. 1995; Foldes et al. 1995). To study the cortical area of long bones, measurements can be obtained in the plane parallel to their generator, using the "axial or transverse measurement" process (Moilanen et al. 2004, Bossy et al. 2002; Bossy et al. 2004). Measurements and images can also be obtained in the perpendicular plane, using the "radial or cross-sectional measurement and imaging" process (André et al. 1980; Lasaygues and Lefebvre 2001; Ouedraogo et al. 2001).

Our group has been focusing on the second type of process, which involves solving inverse scattering problems, but first the corresponding forward problem has to be solved. Several methods have been applied to the forward problem, including integral equation and hybrid finite-element methods and the geometrical theory of diffraction. The latter method provides asymptotic approximations for diffracted fields, which are valid in the case of high frequencies and large distances from the diffracting body. Actually, all these approaches involve the "classical" problem of minimizing the differences between the modeling data and 
the measured values. Several numerical strategies can be used to model the forward and inverse problems simply, efficiently and accurately. The strategy developed in this study was based on the use of ultrasonic tomography and the Born approximation. Ultrasonic tomography, which results from the linearization of the inverse acoustic scattering problem, makes it possible to detect any perturbations (even quite small ones) of the reference surrounding medium. In the case of media with weak inhomogeneities, such as soft tissues, the homogeneous mean medium is taken to be the reference medium. This has led to the development of a "constant background" method, which make it possible at the practical level to perform regular angular scanning with broadband pulses covering the whole spatial frequency spectrum of the object investigated, slice-by-slice. This leads to "reconstructionfrom-projections" algorithms, such as those used in X-ray computed tomography. In the case of media with considerable heterogeneities, such as bones, the problem is a non linear one and there is generally no single solution available. Ultrasound propagation in bone suffers from the severe mismatches encountered between the acoustic properties of bone and those of the surrounding mean medium (soft tissues). However, when the cause of the scattering appears to be quite small and localized in well-known media, a "variable background" method can be used, in which case, the reference background adopted is the water/specimen set (Lefebvre 1994).

In previous studies (Lasaygues et al. 2001), our group established that preliminary in vitro quantitative images of a human adult femur cross-section could be reconstructed using lowfrequency $(<1 \mathrm{MHz})$ ultrasonic reflection tomography. This method consists in assuming the cortical shaft to be a non circular cylindrical elastic cavity, which is taken to be weakly heterogeneous in comparison with the wavelength used (the local fluctuations in the acoustic 
characteristics of a long bone cross-section are weak), immersed in a quasi homogeneous water-like medium. The aim of this study was to assess the cortical thickness of children's thighbones using high-frequency ( $>1 \mathrm{MHz}$ ) diffraction tomography (Lefebvre 1988) associated with an image-processing tool.

Our tomographic approach is first explained and the computer-controlled 2D-ring antenna is also described. Results obtained on experimental phantoms (artificial bone) and real fibulas are presented. Our initial results are promising and suggest that the geometrical characteristics of the bones, which are known to be one of the main factors contributing to the risk of fracture and disease, can be determined using this ultrasonic tomographic method.

\section{ULTRASONIC DIFFRACTION TOMOGRAPHY}

In this section, it is proposed to present the image reconstruction algorithm and to discuss the problem of ultrasonic wave propagation in bone.

\section{The "reference" background}

Assessing the geometrical properties of a non circular cylindrical body, such as a long bone, from an ultrasonic scattered field is a non linear, ill-posed inverse problem. There is generally no single solution to problems of this kind and a suitable modeling procedure (based on firstorder or canonical approximations, for example (Wirgin 1999)) has to be used to avoid obtaining solutions that do not include relevant parameters.

When dealing with weakly inhomogeneous media such as soft biological tissues, a mean medium is chosen as the homogeneous reference background. In this case, the scattering is relatively weak and the problem can be linearized with a Born approximation. If the Green 
function of the unperturbed problem, i.e., the constant background, is known, the forward problem can be solved with the integral equation of Lippman-Schwinger and a far-field solution of the equation can be calculated (Greenleaf 1981). This "constant background" inverse Born approximation method, which requires regular angular slice-by-slice scanning with broadband pulses, yields the spatial frequency spectrum of the object under investigation. The inverse problem is then solved using the classical "reconstruction-fromprojections" algorithms focusing on any perturbations with respect to the reference problem (Kak and Roberts 1986). The details of the complete algorithm were presented in a previous paper (Lasaygues et al. 1997).

When dealing with highly heterogeneous media such as bone (which involves strong contrasts and large objects with respect to the wavelength used), it is not possible to use the Born approximation with a "constant background" directly: hard biological tissues are heterogeneous and their acoustical characteristics differ greatly from those of the surrounding soft tissues (water in the present case: the body is immersed in a water tank). However, in cases such as non destructive testing situations, the focus is generally on flaws, which show up as strong inhomogeneities in well-known media. In this case, one can use a "variable background" inverse Born approximation method to reconstruct the perturbation (Lasaygues 1992; Haddadin 1998). The reference background here is the water/specimen set and the flaw is the perturbation. We have used a similar approach here to the problem of imaging cortical bone thickness, consisting of identifying a water-like cavity in an elastic cylinder. The background, consisting of the cortical part without the hollow and the water, can be defined here as the set and the perturbation is therefore the hollow cavity. 
The problem can be then reduced to studying the difference in acoustic impedance between the cortical part and the water. Some assumptions first have to be made about the properties of the bone.

\section{Bio acoustical considerations}

Bone tissue in humans over $10 \mathrm{y}$ of age can be classified into two broad types, based on the macroscopic porosity. Cortical bone, which is also called compact bone, forms the outer shell of all long bones and its pore volume amounts to about 10\%. Trabecular bone, which is also known as cancellous bone, is much more porous than cortical bone: it has a porosity of about $75 \%$. The shaft of long bones gradually widens towards the ends, the compact wall of the bone becomes thinner and the medullary cavity is lined with an increasingly thick layer of spongy bone.

The acoustic impedance of bones $\left(3\right.$ to $\left.7 \mathrm{~kg} \mathrm{~m}^{-2} \mathrm{~s}^{-1}\right)$ is more heterogeneous than that of the surrounding soft tissues (water $\approx 1 \mathrm{~kg} \mathrm{~m}^{-2} \mathrm{~s}^{-1}$ ) and this feature perturbs the ultrasonic propagation or, more specifically, the refraction, attenuation and scattering of the waves. Conventional medical echography (in the reflection mode only) with high ultrasonic nominal frequencies $(3-13 \mathrm{MHz})$ therefore does not give accurate bone imaging results.

Human cortical bone is generally assumed to consist of a transverse isotropic medium in which the main axis of symmetry is oriented along the longitudinal axis of the diaphysis. This assumption was confirmed by several independent compression and shear wave velocity measurements on various specimens and in various directions of isotropy (Ashman, 1982; Nicholson 2000, Pithioux et al. 2002). In our case, the cross-sections were therefore taken to be isotropic. The long bone shaft forms a long cylindrical cavity (a tube with a diameter of 
about 15 to $20 \mathrm{~mm}$ in the case of the fibula) with a forward bow. This shaft has thick walls of compact bone surrounding a hollow medullary cavity and it mediates the propagation of rather complex waves similar to elastic volume waves. Several types of wave packets can occur, each probably corresponding to a different pathway through the object (through the cortex alone or through the cortex and the medullary cavity) (Cartney and Jeffcott 1987; Cartney et al. 1995) or even to a different propagating mode or type of wave (bulk compressional or shear wave, guided or surface waves) (Anderson and Kak 1984).

Studies conducted by our group have shown that, at low frequencies of [0.5 - 1] MHz, adult femur tomography performed with a signal processing device gives an optimized resolution (Lasaygues and Lefebvre 2001). In this case, the signal contributions used were assumed to correspond to the propagation of a compression wave (the fastest wave). The mean wave velocities were then included, ranging between 2000 and $4000 \mathrm{~m} / \mathrm{s}$ (child and adult bones). In the novel approach presented here, similar assumptions are made, but the nominal frequency of the wave generated was $2.25 \mathrm{MHz}$.

On the one hand, the wavelengths occurring in bone $\left(\lambda_{b} \approx 0.8\right.$ to $\left.1.7 \mathrm{~mm}\right)$ are much larger than the macroscopic porosity and, in bone shafts, than the microstructural level (osteon size $\approx 100$ $\mu \mathrm{m}$ in the case of children's fibulas). Cortical bones will therefore be assumed here to be only weakly heterogeneous (a homogenized equivalent medium) and the ultrasonic waves occurring in the cortical bone will therefore be less severely disturbed. This assumption is in agreement with the "linearized" propagating theory and with the asymptotic approximation.

On the other hand, the wavelength in water $\left(\lambda_{0} \approx 0.6 \mathrm{~mm}\right)$ is smaller than the diameter of bones (about $15 \mathrm{~mm}$ ). Ray theory can be applied here and straight lines running through the object can approximate the propagation paths (Rossman et al. 1989; Langton et al. 1990). 
In the first approximation, the perturbation of the ultrasonic wave propagation is taken to consist only of diffraction and refraction of the incident beam at the interface between the water and the cortical bone and the cortical bone and the inner cavity containing marrow.

The following experimental set-up including eight transducers was used. Transducer number 1 is the transmitter/receiver and the other transducers are receivers. The incident beam runs perpendicular to the tangential point of the scatterer (Fig. 1).

Fig. 1 approximately here

In the reflection and diffraction modes (at angles of less than $\pm 90^{\circ}$, i.e., at transducers nos. 2 , 3 and 7,8 ), the first-arriving signal received was assumed to be the echo from the water/bone interface and the second-arriving signal received was assumed to be the compressional wave propagating due to the echo from the bone/marrow interface. All the other phenomena (shear waves, guided waves etc.) are insignificant or will occur too late to affect the compressional wave processes (fast waves).

In the transmission mode (at angles greater than $\pm 90^{\circ}$, i.e., at transducers nos. 4,5 and 6 ), the signals are abolished and are therefore not taken into account in the signal processing.

(Bossy et al. 2002) and (Nicholson et al. 2002) recently performed numerical simulations and in vivo experiments showing that, in the axial transmission mode, the speed of sound (SOS) of the ultrasound waves was clearly dependent on the cortical thickness. Briefly, the propagation mode is compressional only in thick cortical bone (thickness to wavelength ratio $>0.5$ ) and becomes "guided" in thin cortical bone (ratio < 0.25). In our case, at $2.25 \mathrm{MHz}$, the typical ratio varied from 1 to 10 in a child fibula. The above comment is therefore valid in cross- 
sectional configuration and, in a second approximation, only the compressional mode will be investigated.

Under these circumstances, the perturbation operator is the same as for a homogeneous background (in the particular case of a homogeneous half-space) and all the perturbed parameters will be defined with respect to the characteristics of the medium. The previous tomographic reconstruction algorithm can be used to image shapes and boundaries, within the conditions of the Born approximation.

\section{MATERIAL AND METHOD}

\section{Experimental set-up and procedures}

Since ultrasonic scattering data have to be collected experimentally over a broad range around the specimen in order to cover the full spatial domain, a specially-adapted experimental set-up was developed.

$2 D$-ring antenna. An ultrasonic circular antenna consistent with fast ultrasonic radiofrequency (RF-) signal acquisition (400 ms) was designed and developed by our group. The crown of the antenna has an internal radius of $150 \mathrm{~mm}$ and supports eight fixed transducers distributed over an angle of $360^{\circ}\left(\Delta \theta_{\text {fixed }}=45^{\circ}\right)$. The object to be imaged is placed in the presumed geometrical center of the antenna. The transducers are Imasonic ${ }^{\otimes}$ piezo composite transducers with a $2.25 \mathrm{MHz}$ nominal frequency and cylindrical focusing (in the plane of the slice). The Lecoeur Electronique ${ }^{\circledR}$ multiplexer excites one of the transducers and organizes the signals received by all the transducers. One acquisition (i.e., one sinogram) corresponds to 64 signals (eight emitters by eight receivers) (Table 1). The ultrasonic RF-signals transmitted and 
received, which were composed of 4256 or 8192 samples in the present case, are digitized (8 bit, $40 \mathrm{MHz}$ ). The presumed geometrical centre of the antenna is determined by measuring the time-of-flight between two coaxially-aligned transducers, without the object.

\section{Table 1 approximately here}

\section{Fig. 2 approximately here}

By means of step-by-step motors and an electronic device controlling the mechanical movements, the crown can be made to turn $45^{\circ}$ in stepwise increments of $(1 / 100)^{\circ}$ (we denote the angular increment $\Delta \theta_{\text {variable }}$ ) and to move vertically to perform many slice-by-slice measurements (we note the vertical increment $\Delta \mathrm{l}$ ). In this way, an antenna comprising a larger number of transmitters and receivers was simulated. The signals recorded are then combined according to the angles of diffraction to form the complete sinogram. Transmission signals, corresponding to the direct wave field, were eliminated.

The complete duration of this ultrasonic imaging process (acquisition + signal processing + reconstruction) depends on the signal processing steps and on the capacity of the computer (CPU time). In the examples here, the time required was $1 \mathrm{~min}$ per image. The image is a square consisting of $255 \times 255$ pixels.

Calibration and off-set measurements. Let us consider an object to be imaged. The backscattering measured impulse response of this object at angle $\phi$ can be written

$$
\mathrm{r}(\phi, \mathrm{t})=\mathrm{h}(\phi, \mathrm{t}) * \mathrm{~g}(\phi, \mathrm{t})
$$

where $\mathrm{h}(\phi, \mathrm{t})$ is the impulse response (the mechanical offset) of the whole apparatus comprising the mechanics (the experimental bench) and electroacoustics (the transducers, 
which are assumed to be activated by a perfect electronic pulse $\delta(t))$, and $g(\phi, t)$ is the impulse response of the object.

We are interested in the last quantity, $g(\phi, t)$, and the problem is how to determine it, i.e., how to correct the apparatus deviation, i.e., to "deconvolve" the RF signals $r(\phi, t)$ by the apparatus impulse response $h(\phi, t)$

$$
\mathrm{g}(\phi, \mathrm{t})=\mathrm{r}(\phi, \mathrm{t}) * \mathrm{~h}(\phi, \mathrm{t})
$$

where $*$ designates the "deconvolution " operation.

The problem is now that of evaluating the impulse response of the apparatus $h$. This is done by imaging a very thin copper wire $(0.07 \mathrm{~mm})$, the response of which is taken to be an ideal impulse (Fig. 3 and Fig. 4).

$$
\mathrm{g}(\phi, \mathrm{t})=\delta(\mathrm{t}) \Rightarrow \mathrm{r}(\phi, \mathrm{t})=\mathrm{h}(\phi, \mathrm{t})
$$

The circular data recordings on a thin cylinder allow estimating, for each transducer, the mechanical variations of the position and the water depth to the center of the bench.

Fig. 3 approximately here

Fig. 4 approximately here

For each projection, the "deconvolution " introduced by the mechanical offset was a gap in the signal in comparison with the reference signal obtained at the same angle on the wire sinogram. 


\section{Wall thickness assessment}

Ultrasonic diffraction tomography, with some signal processing refinements, is ideally suited to reconstructing the external boundaries of high-contrast cylindrical bodies. Figure 5.a. shows an example of an ultrasonic reflection tomographic image of a cylindrical plexiglas tube with an external diameter of $16 \mathrm{~mm}$ and an internal diameter of $5 \mathrm{~mm}$, obtained under the experimental conditions described above. Relatively good agreement was observed between the external diameter detected by ultrasound tomography and that measured using calipers.

However, there was a discrepancy as to the position of the boundary of the inner cavity, because the reconstruction process assigns a constant speed of sound (i.e., wave velocity in water $\approx 1500 \mathrm{~m} / \mathrm{s}$ ) to every pixel in the cross-section, which biases the estimates of the inner cavity radius and the thickness. An image processing algorithm was therefore developed to detect the inner cavity radius on the image and to correct the position errors due to the reference speed of sound and the apparent distances.

\section{Fig. 5 approximately here}

In the first step, a polar map is drawn up from the image (mm vs. degrees) (Fig. 5.b.). The center $([0,0] \mathrm{mm})$ of the image is used as the origin of the Cartesian transformation $([0 \mathrm{~mm}$, top left, $0^{\circ}$, bottom left]). The external boundary $\mathrm{Z}_{\mathrm{ext}}$ is detected from the highest color intensity $(\approx 1)$ reached by each vertical line. The "apparent" internal boundary $\left(Z_{\text {app }}\right)$ is established step-by-step, using a "sliding window" algorithm. The "sliding window" algorithm is simply a means of searching for local maximum deposition on the vertical lines of the polar map, which is done using a fixed-size "window" (typically 20 samples) formed 
by a group of contiguous vertical lines. Local maxima are found by moving the window in fixed steps and searching for a window having a higher sum value than that of all of its nearest neighboring windows. In the next step, the actual position $\mathrm{Z}_{\text {int }}$ of the inner boundary is rescaled by assigning the correct velocity values to the pixels corresponding to the shell and to water. This step requires the a priori knowledge of the mean velocity $\mathrm{c}_{\mathrm{b}}$ of the compressional waves to correct the relative inner boundary positioning error and to calculate a new wall thickness in all normal incident directions. The rescaling equation is written as follows:

$$
Z_{\text {int }}=Z_{e x t}+\frac{c_{1}}{c_{0}}\left[Z_{a p p}-Z_{\text {ext }}{ }_{-}^{-}\right.
$$

where $\mathrm{c}_{0}$ is the speed of sound in water.

\section{RESULTS}

The present ultrasonic diffraction tomographic method was applied to one geometricalmimicking phantom and to two real children's fibulas (12 y old). The sample thicknesses varied as a function of the radial position and were measured using calipers at eight locations around the scatterer. Density and velocity were measured using the ultrasonic procedures described in Pithioux et al. 2002. The experimental procedure fulfilled the criteria mentioned in the previous section.

The embedded ultrasonic tomographic software program automatically determined the inner boundaries. On the comparative graphs, each point gives the mean cortical thicknesses and the error bars give \pm 1 standard deviation 


\section{Geometrical-mimicking phantom}

The phantom was a non circular homogeneous isotropic tube made of artificial resin (NEUKADUR ProtoCast $113^{\mathrm{TM}}$ ). Its internal and external diameters measured 17 and $19 \mathrm{~mm}$, respectively, and the inner cavity diameter measured $11 \mathrm{~mm}$ (Fig. 6).

Fig. 6 approximately here

The density of the resin was $1100<\rho_{1}<1200 \mathrm{~kg} / \mathrm{m}^{3}$ and the mean velocity of the compressional wave tested was $\mathrm{c}_{1} \approx 2750 \mathrm{~m} / \mathrm{s}$.

One scanning slice was carried out $2 \mathrm{~mm}$ from the base. We acquired 32 sinograms of 64 signals, with an angular increment $\Delta \theta_{\text {variable }}=1.4^{\circ}$. Results are presented in Fig. 7 and Fig. 8.

Fig. 7 approximately here

Fig. 8 approximately here

Table 2 approximately here

From the ultrasonic tomogram, our algorithm of wall-thickness assessment can automatically and precisely (Table 2) size the outer boundary of the tube with an accuracy of $\pm 0.4 \mathrm{~mm}$ (see $Z_{\text {ext }}$ in Fig. 7). The resolution of the tomogram was sufficiently excellent so that the detection of the highest color intensity is practicable by each vertical line. The accuracy of the inner cavity diameter was also satisfactory, although the mean error was larger. Only the data obtained at location 7 were inaccurate. In Fig. $7, Z_{\text {app }}$ is the apparent boundary obtained by using the "sliding window" algorithm. $Z_{\text {int }}$ is the actual position obtained by using eq $n 4$. 
The algorithm of wall-thickness assessment used to determine the internal boundary was sensitive to the off-centering of the scatterer in the tank. Further studies are now required to assess the robustness of the algorithm versus the identification procedure. The importance of the location at which the caliper measurements are performed also needs to be analyzed, because here, the caliper measurements and the ultrasonic measurements differed by $2 \mathrm{~mm}$. But to conclude, the cortical thickness of artificial bone was on the whole accurately assessed using the present ultrasonic tomographic method.

\section{Child fibulas}

The two child bone samples were fresh fibulas we named "sample A" and "sample B" (12 y old). Dimensions are given in Fig. 9. The inner cavities contained natural marrow.

\section{Fig. 9 approximately here}

The a priori mean velocity was the compression wave velocity, radially measured through a detail cut since the fibula "sample A", and was $2990 \pm 5 \mathrm{~m} / \mathrm{s}$. The density of the cortical material was $1700 \mathrm{~kg} / \mathrm{m}^{3}$. Only one scanning slice was performed, $1.5 \mathrm{~cm}$ from the base. We acquired 32 sinograms consisting of 64 signals, with an angular increment $\Delta \theta_{\text {variable }}=1.4^{\circ}$. Results are presented in Fig. 10 to Fig. 13.

Fig. 10 approximately here

Fig. 11 approximately here

Table 3 approximately here 
Fig. 12 approximately here

Fig. 13 approximately here

Table 4 approximately here

With both fibula samples, the geometry of the outer and inner boundaries was in keeping with the usual proportions, and the cross-sectional thicknesses were in good agreement (Table 3 and Table 4). The differences between the mechanical and acoustical measurements were small $(<0.5 \mathrm{~mm})$, except in some locations: $\mathrm{n}^{\circ} 6$ in the case of "sample $\mathrm{A}^{\prime}$ and $\mathrm{n}^{\circ} 7$ in that of "sample B" (>0.5 mm). There are two possible explanations for the latter differences.

First, the internal boundary assessment algorithm used was sensitive to the image resolution. Since ultrasound tomography is basically a Fourier synthesis problem, the resolution depends on the angular spatial sampling rate and, thus, the number of available projections, which reduced the coverage of the frequency space of the scatterer. Furthermore, the bandwidth of the pulses is limited to almost an octave. To improve the resolution, one can increase the number of transducers placed on the 2D-ring antenna to obtain more than 64 signals and the low and high spectral frequencies can be restored using deconvolution algorithms. For example, one can chose a procedure of Papoulis (1975) that consists of an iterative extension of the bandwidth of the electroacoustic set-up in Fourier space, allowing to reach resolutions of $\lambda / 30$, where $\lambda$ is the wavelength (Lasaygues et al. 2001).

Secondly, the caliper measurements on the internal cavity were performed at eight locations at the base of the bone. However, it is very likely that, at the bone level at which the ultrasonic data recordings were carried out, these dimensions were not exactly the same. 


\section{CONCLUSION}

Within the limits of the Born approximation, we have described a method of performing ultrasonic diffraction imaging of the cortical diaphysis of long bones and obtaining slice-byslice tomographic data in the space-frequency plane. The experiments carried out on real bone using mechanical and electronic steering systems show the results obtained with this method to be accurate. These preliminary results suggest that ultrasonic tomography is one of a means of determining geometrical characteristics such as the cortical thickness of bone, which is known to be an indicator of the state of the fragility of the bone. An important error on the measures would limit the extension of the method to the clinical cases. Furthermore, it would be useful also to discuss transition boundaries between endosteal cortical bone and marrow, more or less heterogeneous and clean, which is an additional challenge for the ultrasonic tomography.

It is thus necessary today to improve the quality of the tomogram to increase the precision of the thickness assessment. Various ways of improving this method will be investigated before increasing the number of antenna components. To increase the number of independent projections, a few rotations of the system could be performed and the transducers could be more regularly distributed. Other algorithms, such as algebraic algorithms, which are more suitable when there are only a few projections, could be also used. The latter algorithms are also known to be suitable for the non linear inversion procedures, which have to be used to deal with the main quantitative imaging problems arising when the contrast is more than a few percent. 


\section{ACKNOWLEGMENTS}

The author is grateful for medical assistance from Dr Ph. Petit and Dr J.-L. Jouve from Public Assistance Hospitals of Marseille, "Timone" Children's Hospital. This work benefited from the very fruitful help of J.-P. Lefebvre and S. Mensah. Many thanks to E. Debieu, A. Cosquer, S. Devic, J.-M. Corneloup, A. Kerjoant and V. Cardinalli for their technical assistance. 


\section{REFERENCES}

Anderson A.H. and Kak A.C. The application of ray tracing towards a correction for refracting effects in computed tomography with diffracting sources. School of Electrical Engineering, TR-EE 84-14, Purdue University, West Lafayette 1984.

Andre M.P., Craven J.D., Greenfield M.A. and Stern R. Measurement of the velocity of ultrasound in the human femur in vivo. J. of Med Phys. 1980;7(4):324-30.

Ashman R.B. Ultrasonic determination of the elastic properties of cortical bone: technique and limitations. PhD Thesis Department of Biomedical Engineering, Tulane University 1982. Baert A.L. and Sartor K. Emergency Pediatric Radiology, in Medical Radiology, Diagnostic Imaging, H.Carty (Ed.), Springer-Verlag 2002.

Bossy E., Talmant M. and Laugier P. Effect of bone cortical thickness on velocity measurements using ultrasonic axial transmission: A 2D simulation study. J. Acoust. Soc. Am., 2002;112:297-307.

Bossy E., Talmant M. and Laugier P. Three-dimensional simulations of ultrasonic axial transmission velocity measurement on cortical bone models. J Acoust Soc Am., 2004; $115: 2314-2324$.

Enns P., Pavlidis T., Stahl J.P., Horas U. and Schnettler R. Sonographic detection of an isolated cuboid bone fracure not visualized on plain radiographs. Journal of Clinical Ultrasound, 2004; 32(3):154-157.

Falcini F., Bindi G., Ermini M., Galluzzi F., Poggi G., Rossi S., Masi L., Cimaz R. and Brandi M.L. Comparison of quantitative calcaneal ultrasound and Dual Energy X-ray 
Absorptiometry in the evaluation of osteoporotic risk in children with chronic rheumatic diseases. Calcified Tissue International, 2000;67(1):19-23.

Foldes J., Rimon A., Keinan D.D. and Popovtzer M.M. Quantitative ultrasound of the tibia: A novel approach for assessment of bone status. Bone 1995,17:363-367.

Greenleaf J.F. Computerized transmission Tomography. In methods of Experimental Physics, Ultrasonics, 1981;19:563-589.

Haddadin O.S. Ultrasound inverse scattering for tomographic imaging and self-focussing arrays. Ph.D. thesis, University of Michigan, 1998.

Halaba Z.P.and Pluskiewicz W. Quantitative ultrasound in the assessment of skeletal status in children and adolescents. Ultrasound in Med. \& Biol., 2004;30(2):239-243.

Rand T., Ritschl P., Trattnig S., Breitenseher M., Imhof H. and Resnick D. Imaging of bone and soft tissue tumors. A case study approach. Springer-Verlag 2001.

Kak A.C. and Roberts B.A. Reconstruction from Projections: Applications in Computerized Tomography. Handbook of Pattern Recognition and Image Processing, 1986:649-693.

Langton C.M., Ali A.V., Riggs C.M., Evans G.P. and Blonfield W. Measurement of ultrasonic velocity broadband attenuation in cortical and cancellous bone. Clin. Phys. Physiol. Meas. 1990;11:243-249.

Lasaygues P. Etude de l'écho d'une fissure, traitement de signaux par analyse en ondelettes en contrôle non destructif. (in French) Ph.D. Thesis, University of Aix-Marseille II, 1992. Lasaygues P., Lefebvre J.P. and Mensah S. High Resolution Low Frequency Ultrasonic Tomography. Ultrasonic Imaging 1997;19:278-293.

Lasaygues P. and Lefebvre J.P. Cancellous and cortical bone imaging by reflected tomography. Ultrasonic Imaging, 2001;23:55-68. 
Lefebvre J.P. La tomographie ultrasonore en réflexion. (in French) J. Acoustique, 1988;1:123-128.

Lefebvre J.P. Progress in linear inverse scattering imaging : NDE application of Ultrasonic Reflection Tomography. In Inverse Problem in Engineering Mechanics, in A.A.Balkema (Ed), Rotterdam/Brookfield, 1994:371-375.

Mc Cartney R.N., Jeffcott L.B. and Mc Carthy R.N. Transverse path of ultrasound waves in thick-walled cylinders. Med. \& Biol. Eng. \& Compt., 1995;33:551-557.

Mc Cartney R.N. and Jeffcott L.B. Combined 2.25 MHz ultrasound velocity and bone mineral density measurements in the equine metacarpus and their in vivo applications. Med. \& Biol. Eng. \& Comput. 1987;25:620-626.

Mayr J.M., Grechenig W. and Höllwarth M.E., Musculoskeletal ultrasound in pediatric trauma. European Journal of Trauma, 2004;30(3), 150-160.

May D.A., Disler D.G., Jones E.A. and Pearce D.A. Using sonography to diagnose an unossified medial epicondyle avulsion in a child. American Journal of Roentgenology, 2000;174:1115-1117.

Moilanen P., Kilappa V., Nicholson P.H.F., Timonen J. and Cheng S. Thickness sensitivity of ultrasound velocity in long bone phantoms. Ultrasound Med. And Biol. 2004;30(11):15171521.

Nicholson P.H.F., Strelitzki R., Cleveland R.O. and Bouxsein M.L. Scattering of ultrasound in cancellous bone: prediction from a theoretical model. Journal of Biomechanics 2000;33: 503-506. 
Nicholson P.H.F., Moilanen P., Karkkainen T., Timonen J. and Cheng S Guided ultrasonic waves in long bone: Modelling, experiment and in vivo application. Physil Meas 2002;23:755-768.

Ouedraogo E., Lasaygues P., Lefebvre J.P., Gindre M., Talmant M., and Laugier P. Contrast and velocity ultrasonic tomography of long bones. Ultrasonic Imaging 2002;24:135-146.

Papoulis A., A new algorithm in spectral analysis and band-limited extrapolation, in IEEE Trans. Circuits Syst. 1975;22:735-742.

Pithioux M., Lasaygues P. and Chabrand P. An ultrasonic methods to describe mechanical properties of compact bone. Journal of Biomechanics 2002;35:961-968.

Rossman P., Zagzebski J., Mesina C., Sorenson J. and Mazess R. Comparison of speed of sound and ultrasound attenuation in the os calcis to bone density of the radius, femur, lumbar spine. Clin. Phys. Physiol. Meas. 1989;10:353-360.

Stegman M.R., Heaney R.P., Travers-Gustafson D. and Leist J. Cortical ultrasound velocity as an indicator of bone status. Osteo. Int. 1995;5:349-353.

Wirgin A Some quasi-analytic and numerical methods for acoustical imaging of complex media. In Wirgin A. (Ed.), Wavefield inversion, Springer, Wien, 1999.

Wear K.A. Autocorrelation and cepstral methods for measurement of tibial cortical thickness. IEEE Transactions on Ultrasonics, Ferroelectrics, \& Frequency Control 2003;50(6):655-660. 
Table 1. Acquisition sequences.

Table 2. Comparison between calipers and ultrasound-derived dimensions (geometricalmimicking phantom).

Table 3. Comparison between calipers and ultrasound-derived dimensions ("sample A").

Table 4. Comparison between calipers and ultrasound-derived dimensions ("sample B").

Fig. 14. Theoretical diffraction tomography with eight transducers. Transducers nos. 1 to 8 are transmitters (and receivers) and the other transducers are receivers.

Fig. 15. 2D-ring circular antenna.

Fig. 16. 2.25 MHz-ultrasonic diffracted sinograms of a thin copper wire $(0.07 \mathrm{~mm}),(32$ rotations, $\Delta \theta_{\text {variable }}=1.4^{\circ}$. View angles: (a) $0^{\circ}$ (first sinogram), (b) $21.09^{\circ}$ (middle sinogram) and (c) $43.59^{\circ}$ (last sinogram)).

Fig. 17. 2.25 MHz-ultrasonic diffracted tomography of a thin copper wire $(0.07 \mathrm{~mm})$.

Fig. 18. Assessment of the thickness of a cylindrical plexiglas tube. (a) Reflection Tomography. (b) Polar map, $Z_{\text {ext }}$ is the external boundary, $Z_{\text {app }}$ and $Z_{\text {int }}$ are the "apparent" and actual boundaries of the inner cavity. (c) Polar representation.

Fig. 19. NEUKADUR ProtoCast $113^{\mathrm{TM}}$ resin geometrical-mimicking phantom.

Fig. 20. 2.25 MHz-ultrasonic diffracted tomography of a geometrical-mimicking phantom.

Fig. 21. Cortical thickness depending on the measurement site, using mechanical calipers and a $2.25 \mathrm{MHz}$-ultrasonic tomogram (on a geometrical-mimicking phantom). (a) Initial tomogram. (b) Polar map, $Z_{\text {ext }}$ is the external boundary, $Z_{\text {app }}$ and $Z_{\text {int }}$ are the "apparent" and the actual boundaries of the inner cavity. (c) Mean-thickness.

Fig. 22. Geometrical dimensions of child fibulas.

Fig. 23. 2.25 MHz-ultrasonic diffracted tomography of a child fibula ("sample A"). (a) Initial tomogram. (b) Mean-thickness.

Fig. 24. Cortical thickness at various measurement sites, determined using mechanical calipers and 2.25 MHz-ultrasonic tomogram ("sample A").

Fig. 25. 2.25 MHz-ultrasonic diffracted tomography of a child fibula ("sample B"). (a) Initial tomogram. (b) Mean-thickness.

Fig. 26. Cortical thickness at various measurement sites, using mechanical calipers and 2.25 $\mathrm{MHz}$-ultrasonic tomogram ("sample B"). 
Table 1

\begin{tabular}{|c|c|c|c|}
\hline & Transmitter $^{\circ}$ & Receiver $^{\circ}$ & Configuration \\
\hline 1 & 1 & 1 & Backscattering \\
\hline 2 & 1 & 2 & \\
\hline 3 & 1 & 3 & \\
\hline 4 & 1 & 4 & Transmission \\
\hline 5 & 1 & 5 & \\
\hline 6 & 1 & 6 & \\
\hline 7 & 1 & 7 & Backscattering \\
\hline 8 & 1 & 8 & \\
\hline 9 & 2 & 1 & Transmission \\
\hline 10 & 2 & 2 & Backscattering \\
\hline 11 & 2 & 3 & \\
\hline.. & 2 & 6 & \\
\hline 14 & $\ldots$ & 8 & \\
\hline.. & 8 & & \\
\hline 64 & & & \\
\hline
\end{tabular}


Table 2

\begin{tabular}{|c|c|c|}
\hline Location & Calipers (mm) & Mean-values (mm) \\
\hline $\mathrm{L}$ & 19 & 19.4 \\
\hline 1 & 17 & 16.6 \\
\hline $\mathrm{a}$ & 11 & 11.5 \\
\hline $\mathrm{b}$ & 11 & 10.9 \\
\hline 1 & 5 & 5.60 \\
\hline 2 & 3.2 & 2.80 \\
\hline 3 & 3 & 2.80 \\
\hline 4 & 3.2 & 3.25 \\
\hline 5 & 3 & 2.95 \\
\hline 6 & 3.2 & 3.40 \\
\hline 7 & 3 & 1.75 \\
\hline 8 & 3.2 & 2.80 \\
\hline
\end{tabular}


Table 3

\begin{tabular}{|c|c|c|}
\hline Location & Calipers $(\mathrm{mm})$ & Mean-values $(\mathrm{mm})$ \\
\hline $\mathrm{L}$ & $17 \pm 2$ & 16.3 \\
\hline 1 & $13.5 \pm 2$ & 14.5 \\
\hline $\mathrm{a}$ & $7 \pm 0.5$ & 9 \\
\hline $\mathrm{b}$ & $5.5 \pm 0.5$ & 6.8 \\
\hline 1 & 2.6 & 2.35 \\
\hline 2 & 3.2 & 3.25 \\
\hline 3 & 3 & 3.10 \\
\hline 4 & 3.5 & 3.7 \\
\hline 5 & 4.5 & 4.15 \\
\hline 6 & 3.5 & 2.95 \\
\hline 7 & 3.3 & 3.10 \\
\hline 8 & 4.5 & 4.30 \\
\hline
\end{tabular}


Table 4

\begin{tabular}{|c|c|c|}
\hline Location & Calipers $(\mathrm{mm})$ & Mean-values $(\mathrm{mm})$ \\
\hline $\mathrm{L}$ & $14 \pm 2$ & 14 \\
\hline 1 & $11 \pm 2$ & 13.23 \\
\hline $\mathrm{a}$ & $7.5 \pm 0.5$ & 8.82 \\
\hline $\mathrm{b}$ & $6.5 \pm 0.5$ & 8 \\
\hline 1 & 3.1 & 3.55 \\
\hline 2 & 1.9 & 1.90 \\
\hline 3 & 2.3 & 2.05 \\
\hline 4 & 2.5 & 2.65 \\
\hline 5 & 2.7 & 2.80 \\
\hline 6 & 2.5 & 2.35 \\
\hline 7 & 1.9 & 1.45 \\
\hline 8 & 2 & 1.75 \\
\hline
\end{tabular}




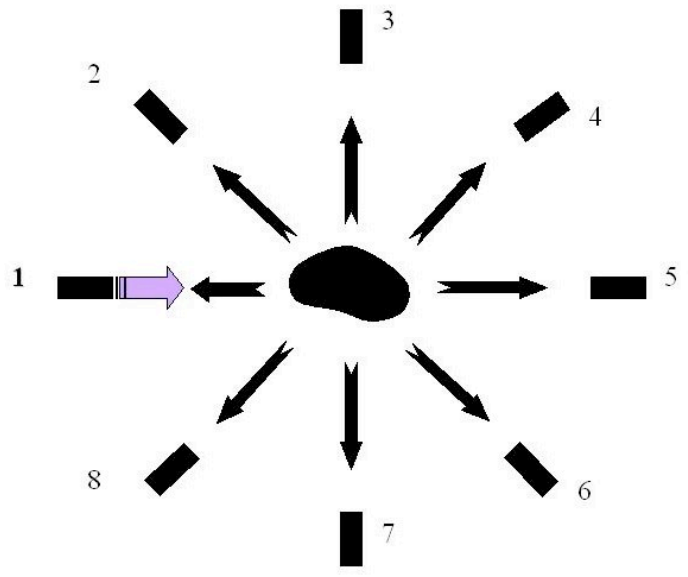

Fig. 1 


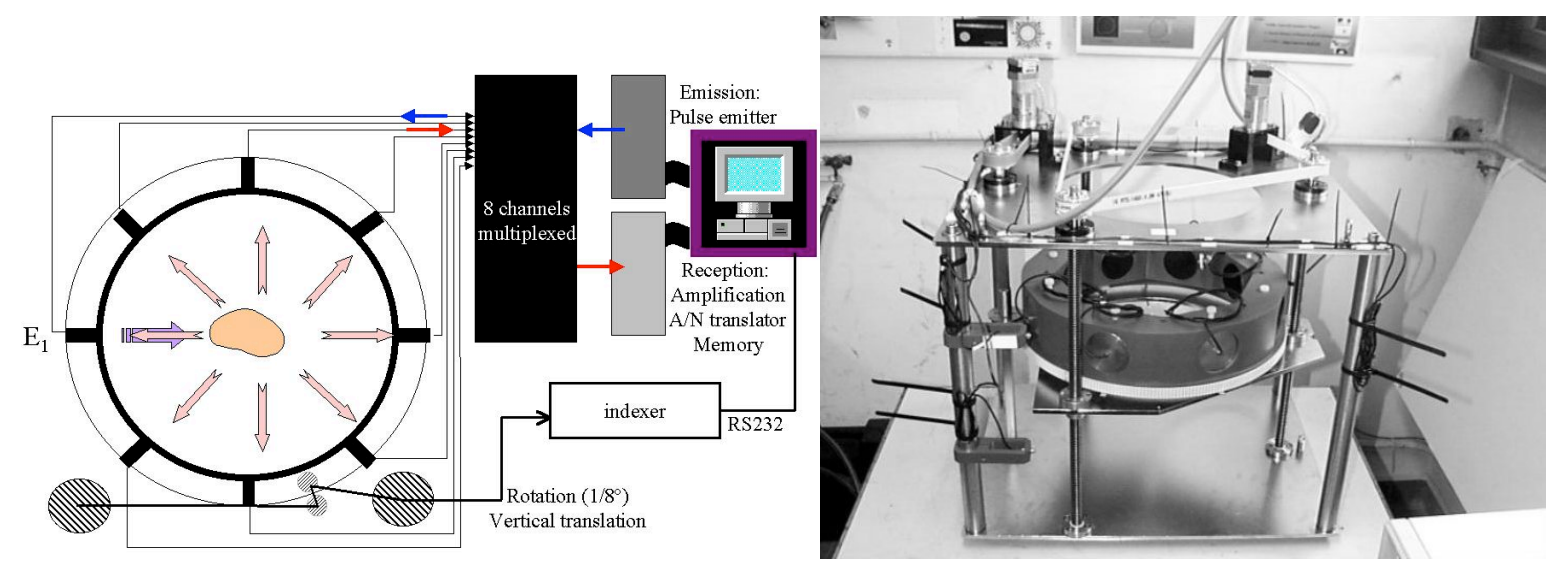

Fig. 2 


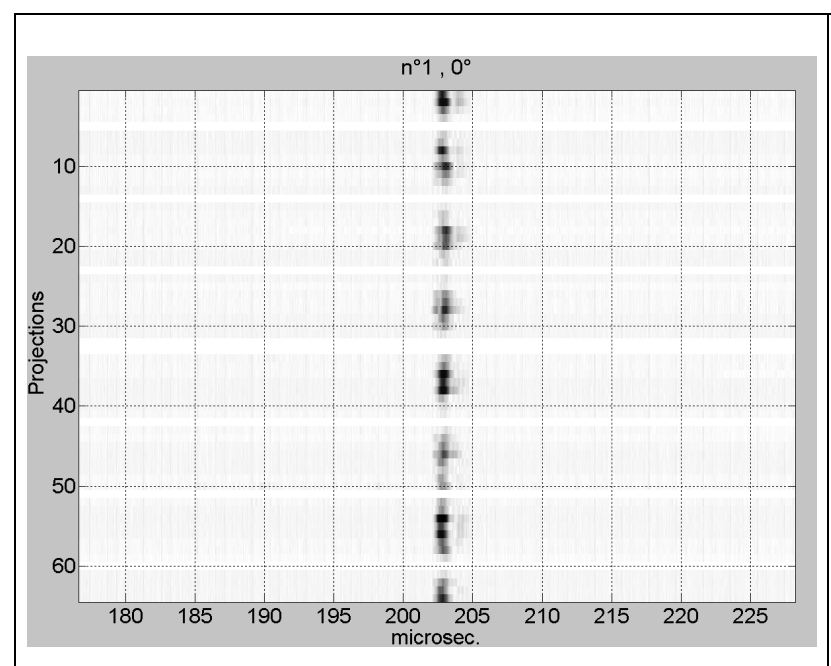

(a)

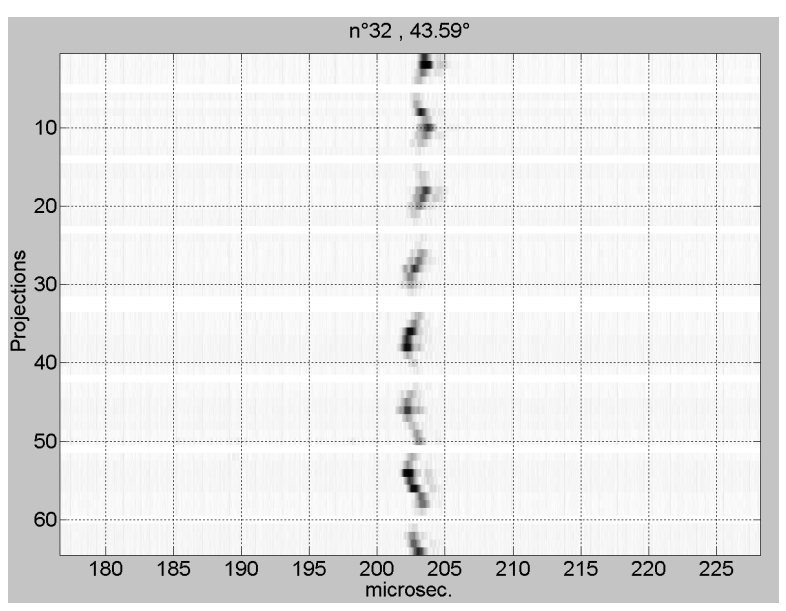

(c)

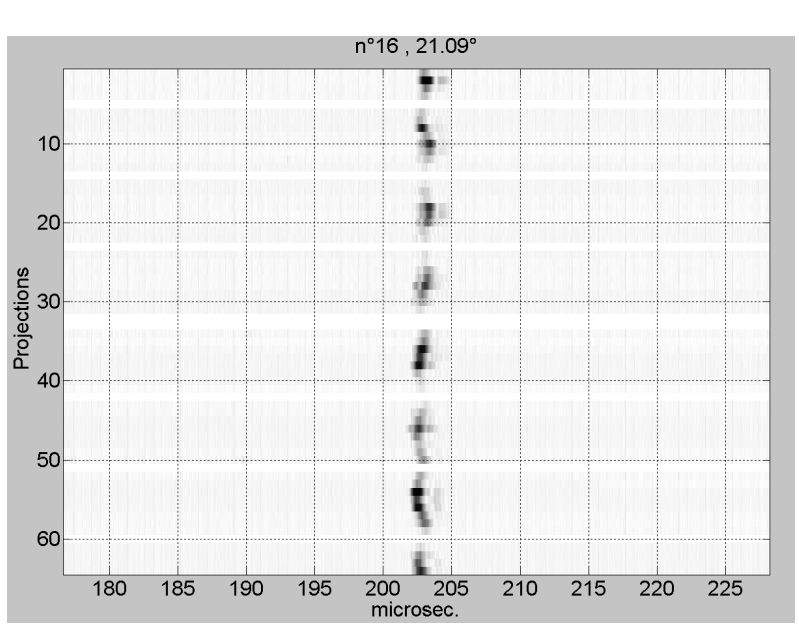

(b)

Fig. 3 


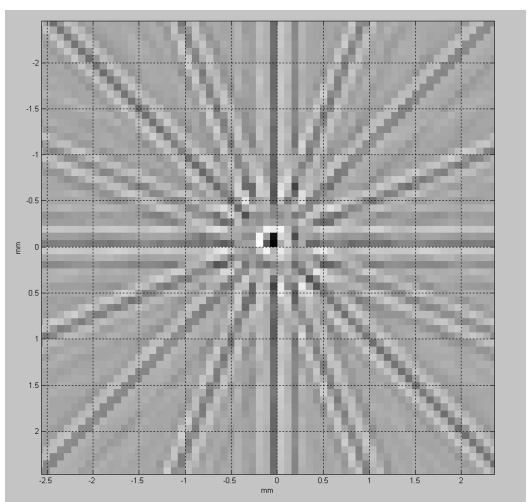

Fig. 4 


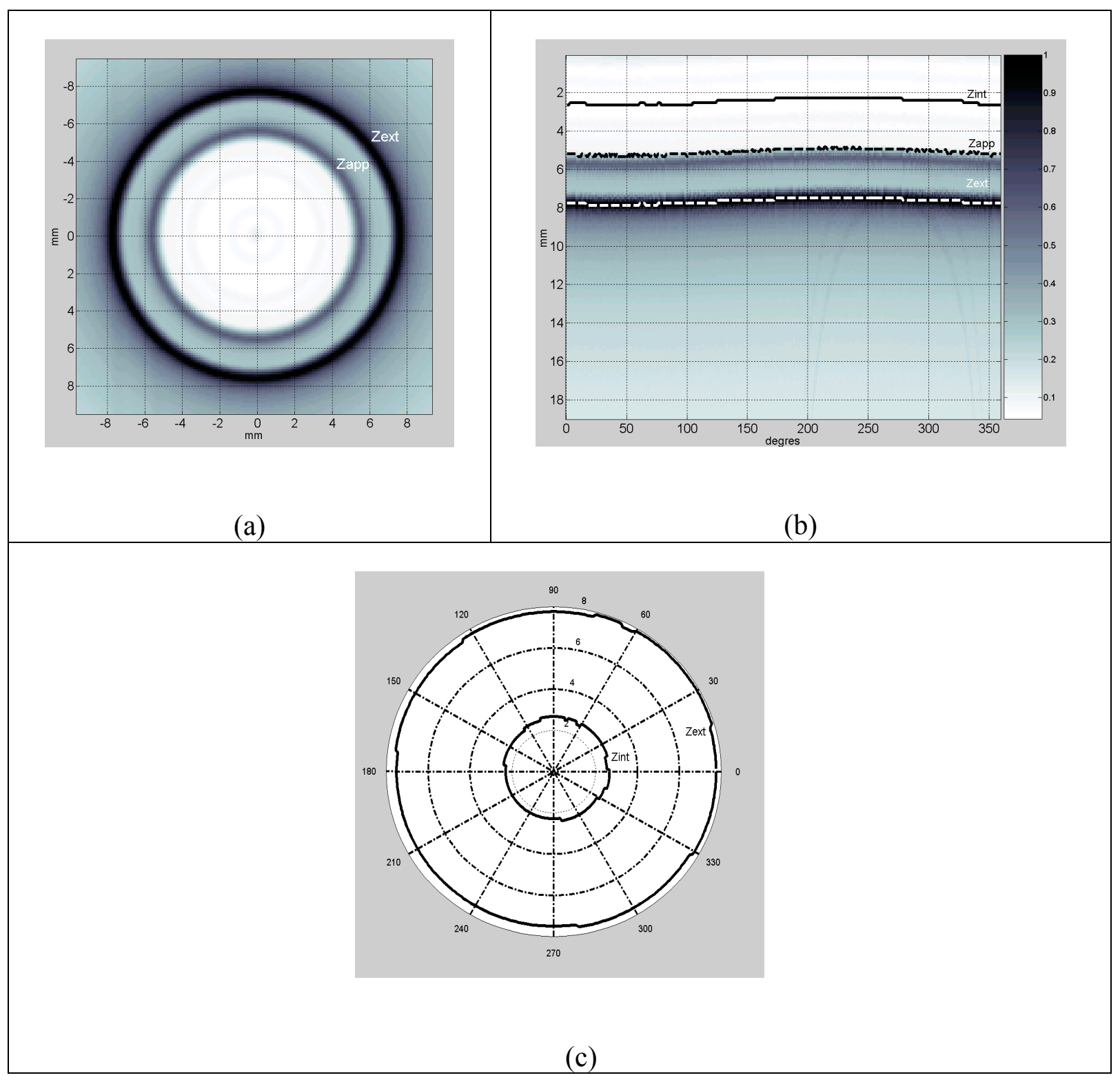

Fig. 5 


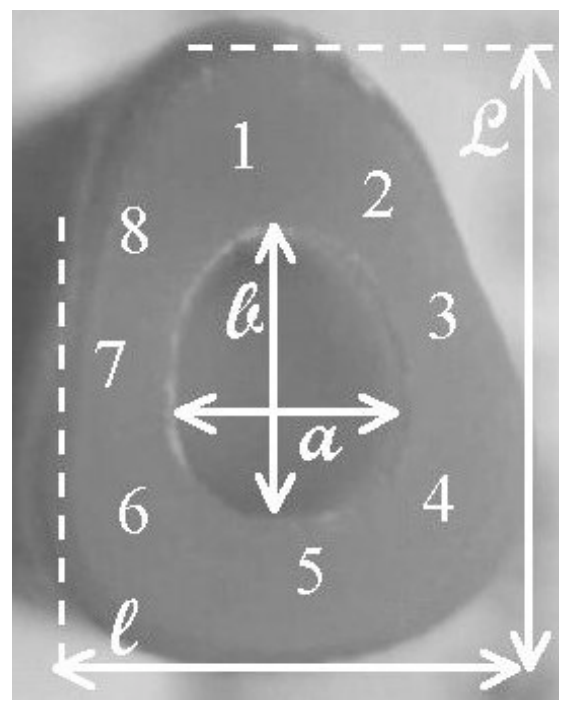

Fig. 6 


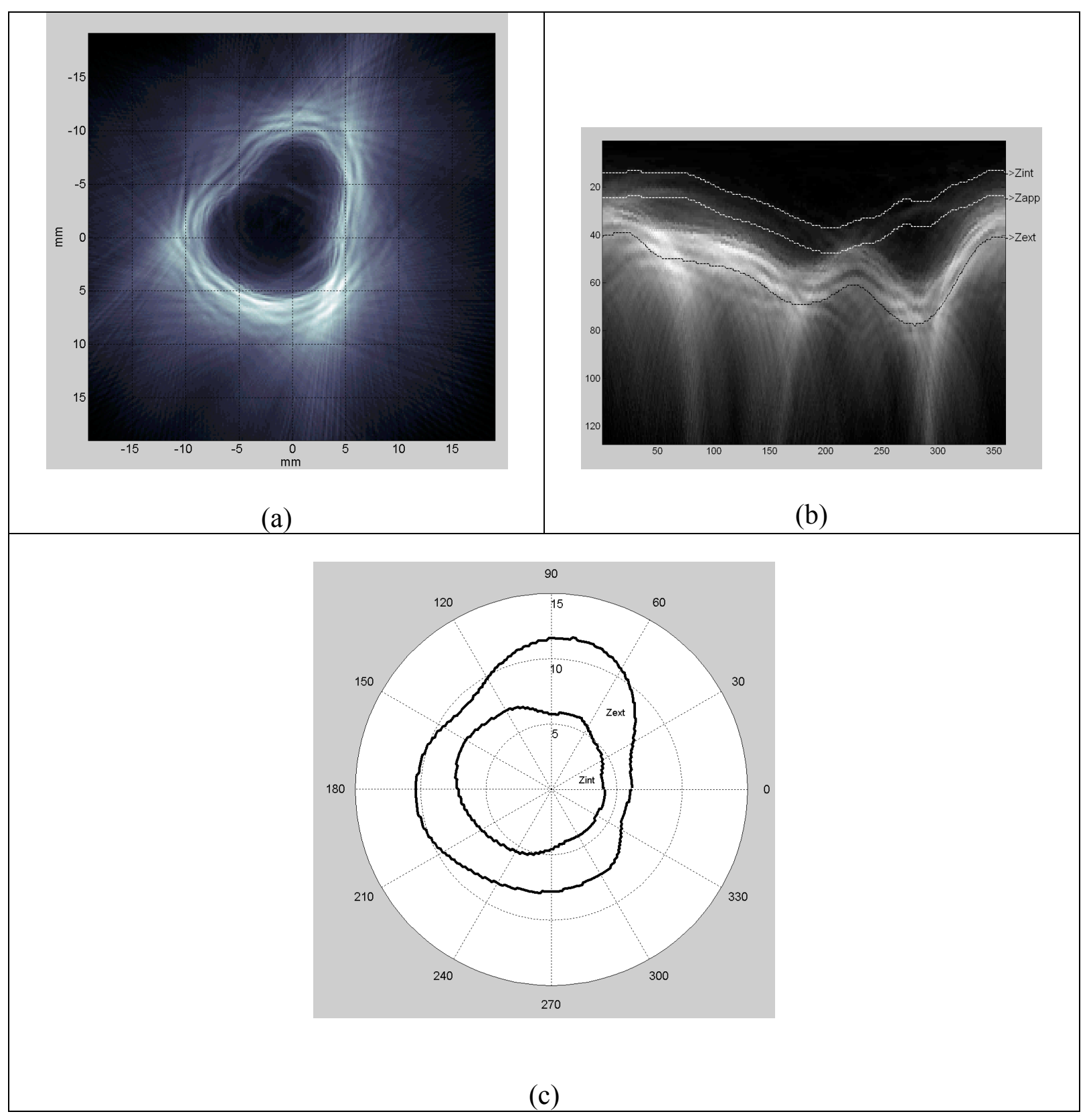

Fig. 7 


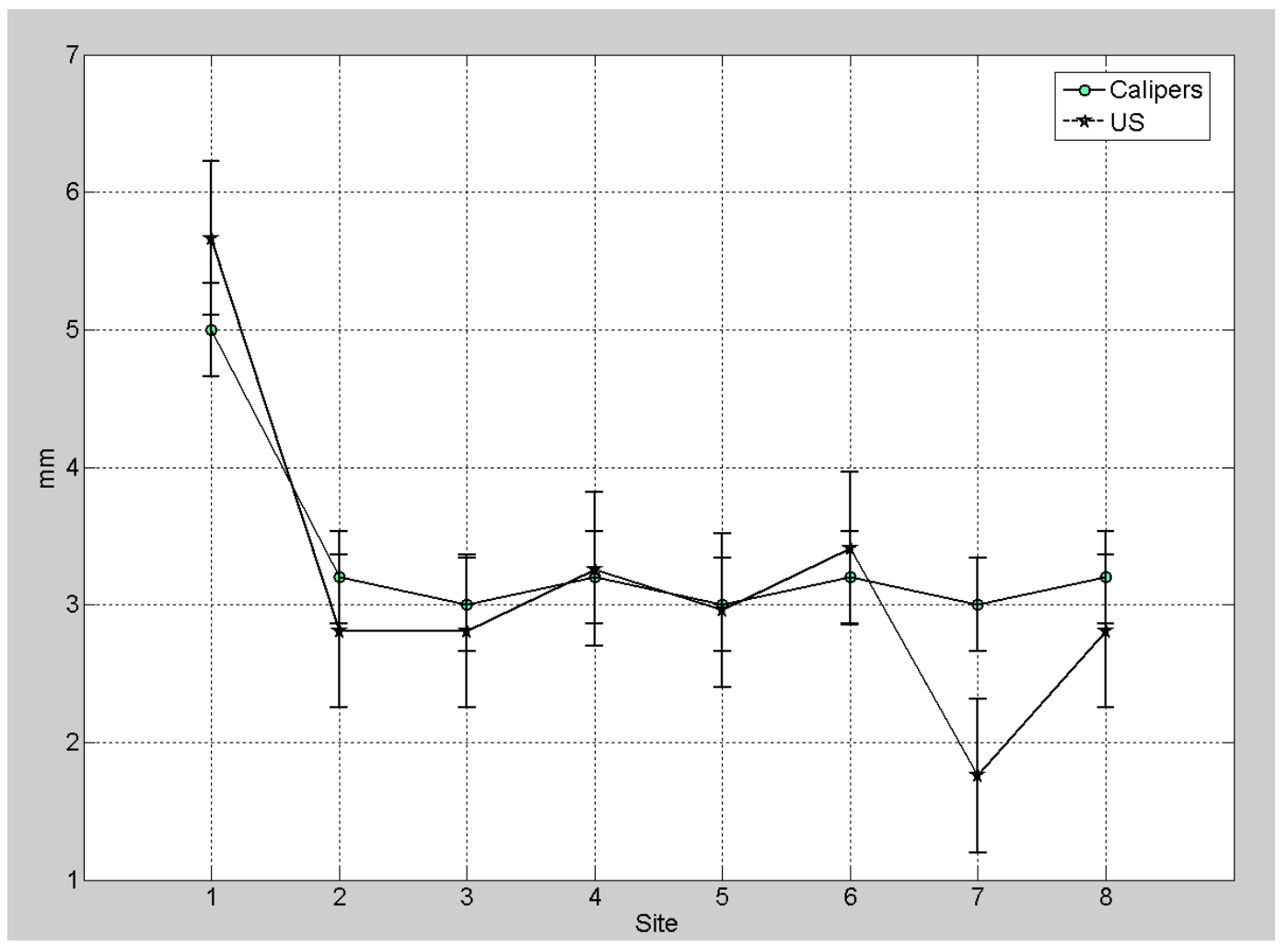

Fig. 8 


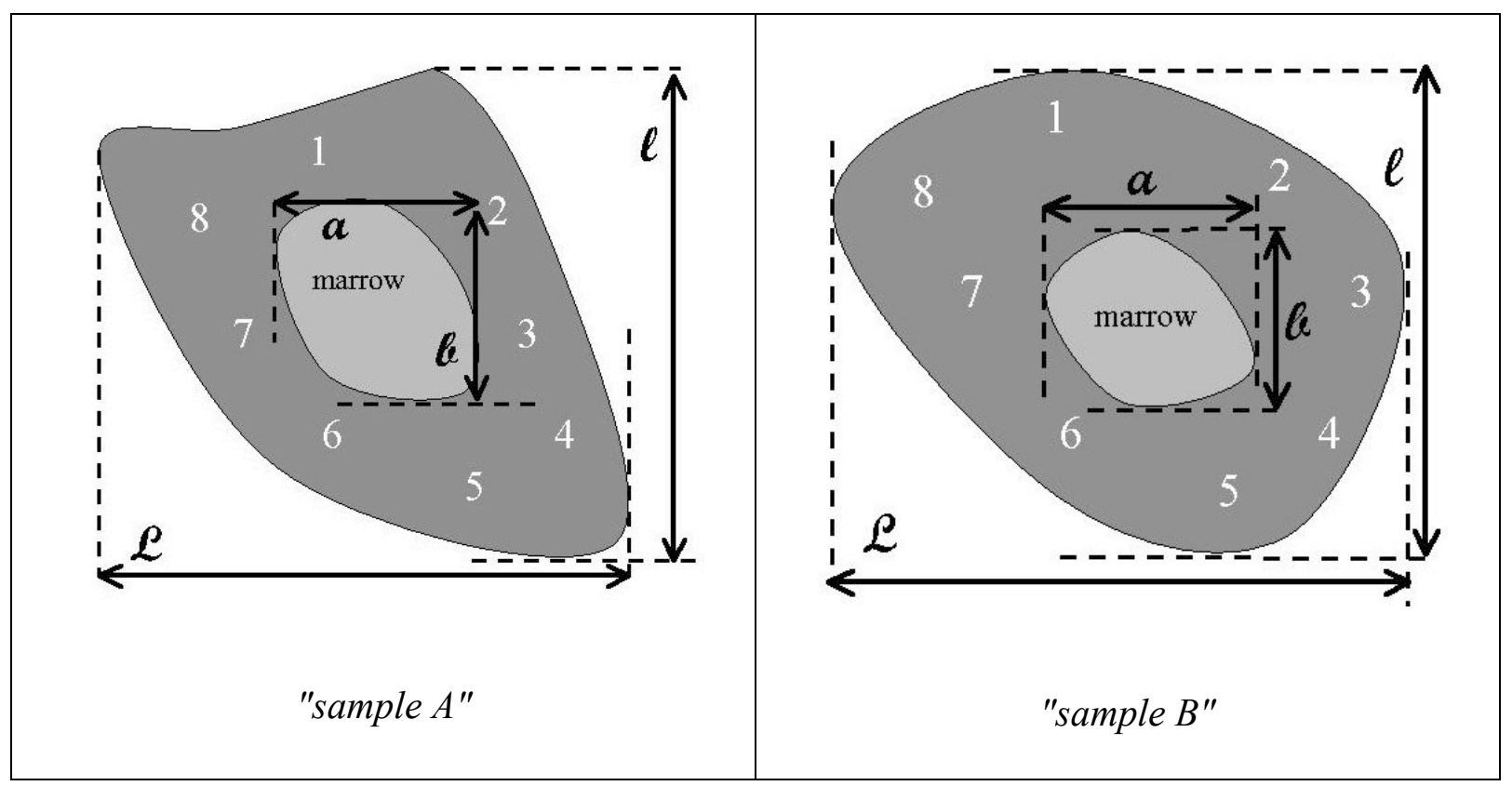

Fig. 9 


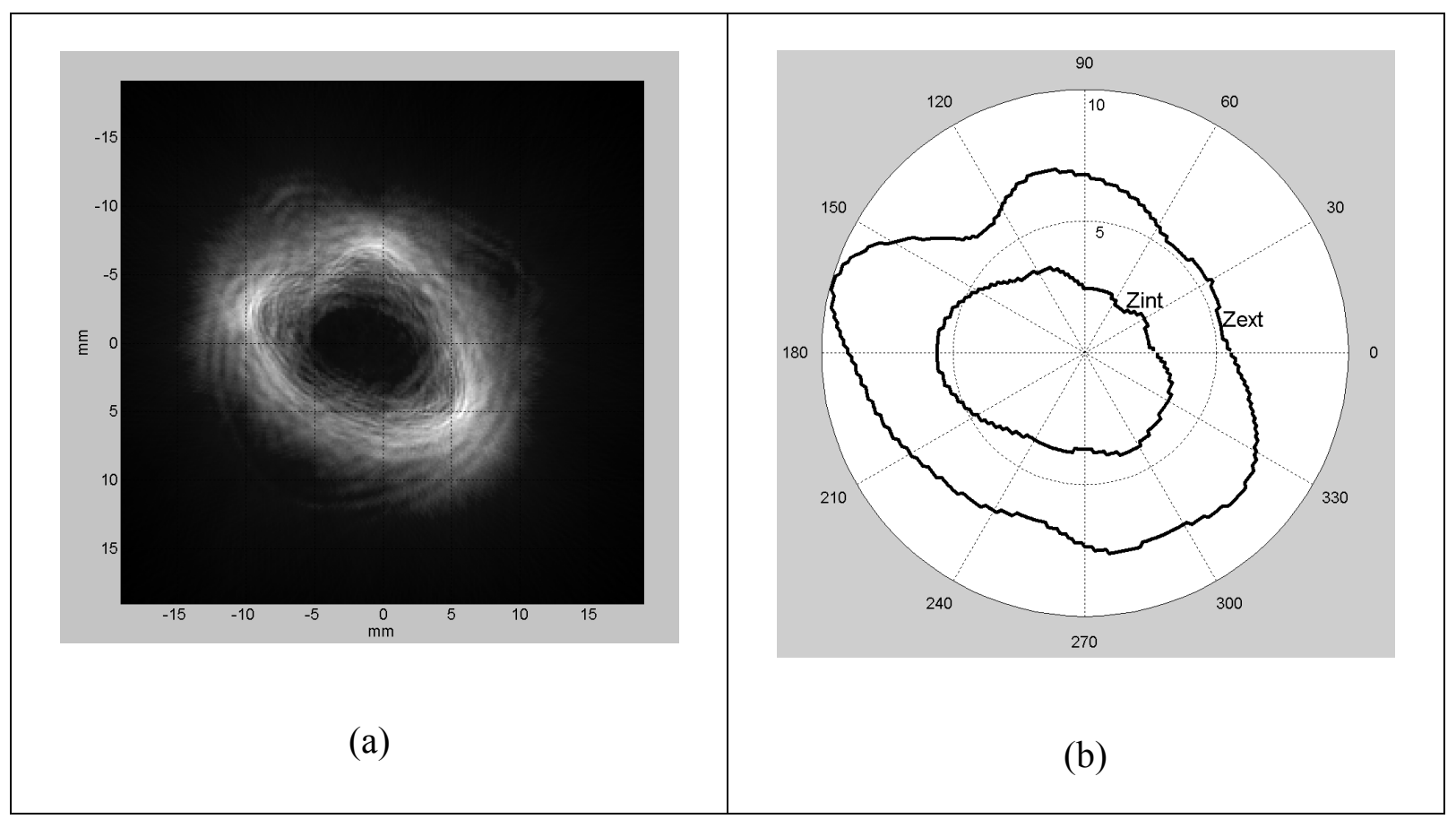

Fig. 10 


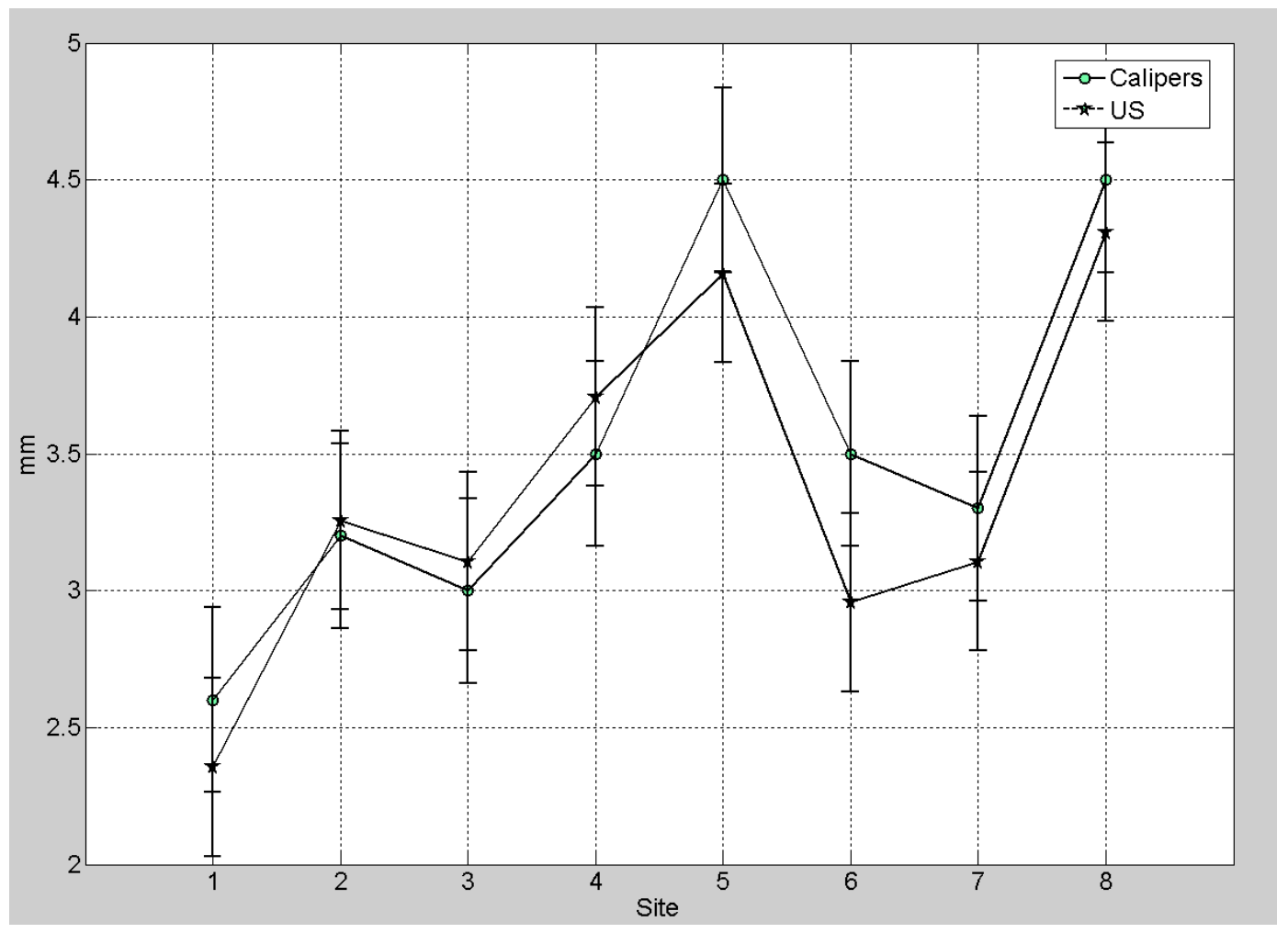

Fig. 11 


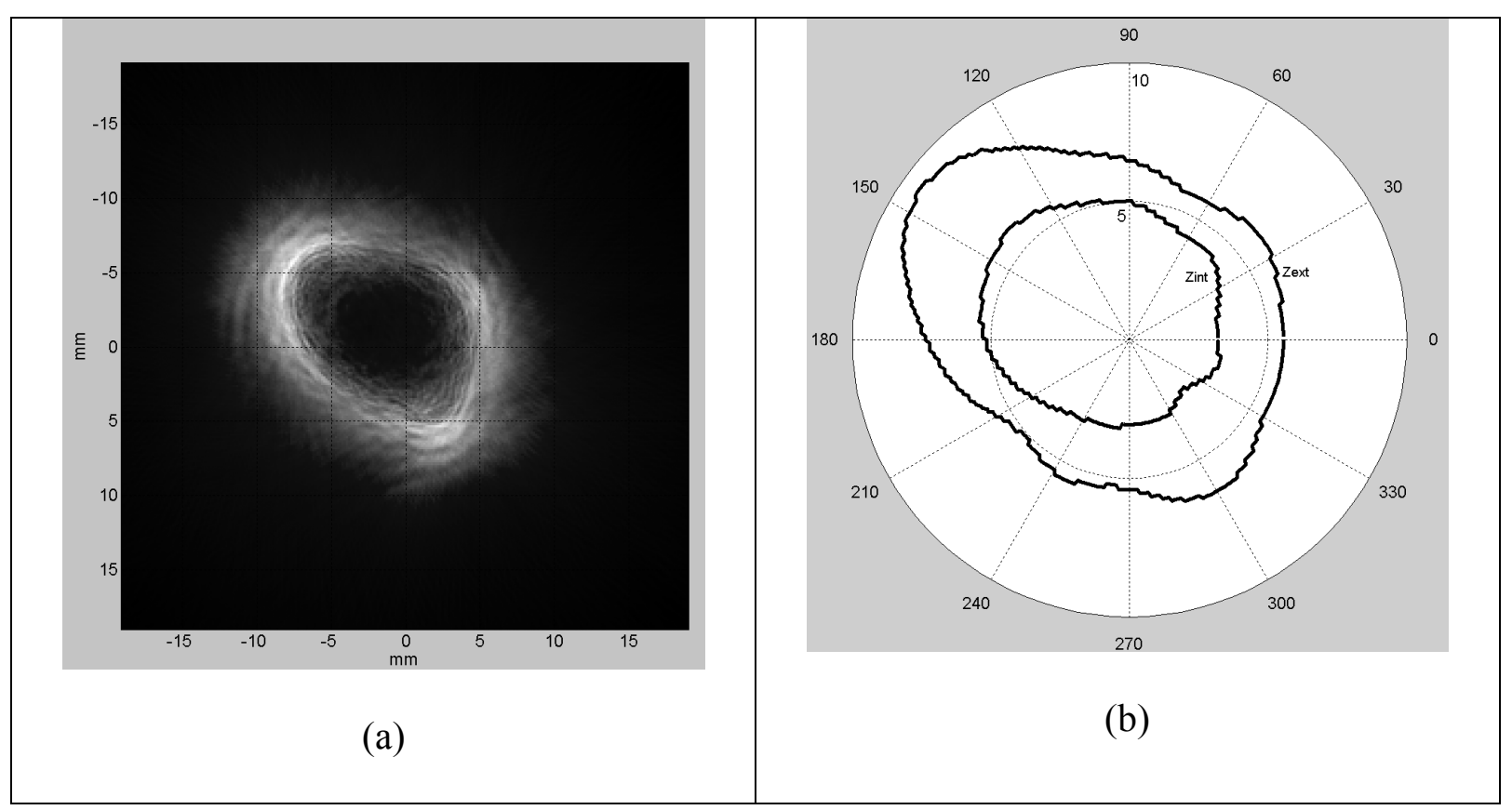

Fig. 12 


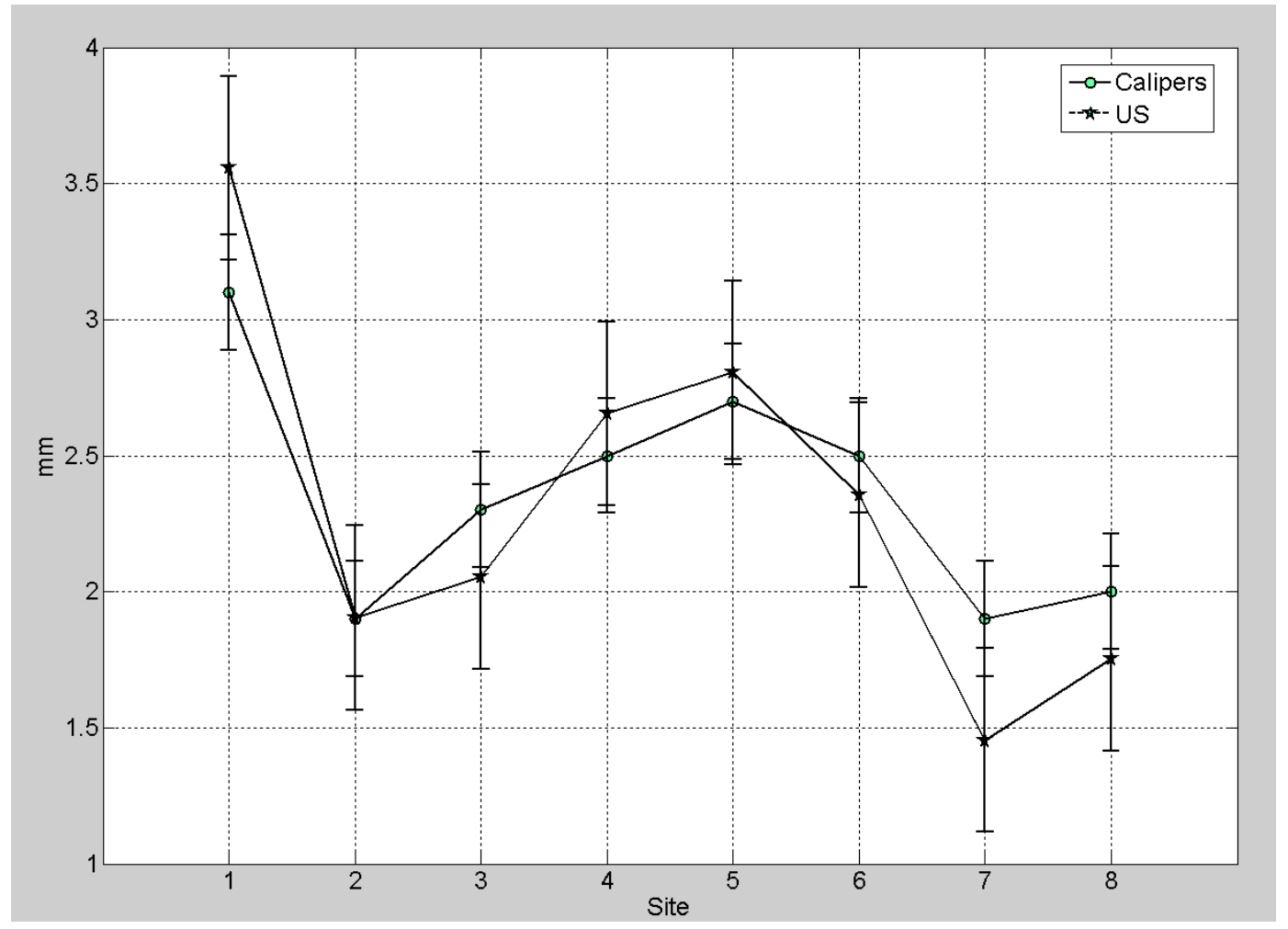

Fig. 13 